$\xi=-1$

\title{
Enhancing Data Security Using Audio-Video Steganography
}

\author{
Rambabu Mudusu' ${ }^{*}$, A. Nagesh ${ }^{2}$, M. Sadanandam ${ }^{3}$ \\ ${ }^{1}$ Assoc.Professor, Department of Computer Science \& Engineering, KG Reddy College of Engineering \& Technology, Hyderabad. \\ ${ }^{2}$ Associate Professor, M.Tech(CSE), Ph.D, Department of Computer Science and Engineering, Kakatiya University, Warangal. \\ E-mail:akknagesh@ rediffmail.com \\ ${ }^{3}$ Professor, M.Tech(CSE),Ph.D, Department of Computer Science and Engineering, Mahathma Gandhi Institute of Technology, \\ Hyderabad.E-mail:sadanb4u@yahoo.co.in \\ *Corresponding author E-mail:rams.crypto@kgr.ac.in
}

\begin{abstract}
Steganography may be a strategy for concealing any mystery information like content, picture, sound behind distinctive cowl document .In this paper we have a tendency to planned the mix of image steganography associated sound steganography with confront acknowledgment innovation as an instrument for verification. The purpose is to shroud the mystery information behind sound and therefore the beneficiary's face image of video, because it may be a use of various still casings of images and sound. During this technique we've chosen any casing of video to shroud beneficiary's face image and sound to hide the mystery data. Affordable calculation, maybe, increased LSB and RSA rule is been utilised to shroud mystery content and movie. PCA rule is employed for confront acknowledgment. The parameter for security and verification ar gotten at collector and transmitter facet that ar exactly indistinguishable, consequently the knowledge security is dilated.
\end{abstract}

Keywords: Steganography, python, principle component analysis, least vital bit, RSA rule then forth.

\section{Introduction}

The term 'steganography' exemplifies the act of subtly inserting data into computerised mediums together with video, image and sound records. Despite the actual fact that steganography is often connected with evil exercises, fairly it affirms many qualities that render it valuable in modern security applications. Data security assumes an important half in internet correspondence with the current time of innovation. it's a standout amongst the foremost troublesome problems currently days. it's vital to people submitting e-exchanges like internet based mostly looking, money exchange then forth. Steganography is that the technique that's used for secure correspondence. The rule of steganography is to veil the terribly closeness of correspondence; it shrouds the presence of message. This strategy is mostly wont to avert not pondered recipient's assaults of unapproved get to. Not solely associate instrument for lawbreakers to impart mystery information regarding a complicated channel, steganography is to boot used as a wise strategy for guaranteeing honorableness of computerised media antiquities and for ID of same. This utilization of steganography takes into thought identifying proof photos golf stroke away further information to substantiate each the temperament of the topic and additionally the believability of the image. Sound steganography is one in every of the acknowledge data concealing procedures that installs mystery information in sound signs. It depends on the covering impact of Human sound-related framework (HAS). this means seven days sound is inaudible among the sight of the substantial one. data storage away in sound signs has numerous applications, let's say, insurance of proprietary sound signs and firmly covering correspondence data. Steganography truly implies secured composing. Its can probably shroud the approach that correspondence is happening. this is often accomplished by utilizing a (somewhat vast) cowl document and putting in the (somewhat short) mystery message into this record. the end result is that the stego document that contains the mystery message. Presently, it's increasing new prominence with the ebb and flow trade requests for advanced watermarking and process of sound and video Steganography has seen exponential utilization since the Nineties. Governments, military, organizations, and personal nationals all over throughout the planet currently utilize steganography for security and protection reason. In our venture a sound steganography system is propose to shroud message motion in sound within the amendment area. The message motion in any organization is disorganized and sent by sound while not uncovering the presence to anyone. The character of stego record is calculable by PSNR. The character of separated mystery message flag is calculable by SNR. The arrangement is recover into associate different proportionate sight and sound framework records like photos, video or sound, that is being hid within another question. For sound video steganography increased LSB and RSA calculation is employed to hide content and beneficiary image. Face acknowledgment technique utilizing PCA calculation is employed for giving verification.

\section{Problem statement}

As the use of internet on the earth is swollen extremely, henceforward all ar needed bigger security. \{the internet|the online|the net \} designers ar faithfully tries to create web free from sticking out. For that there ar various systems and calculations ar planned. \{they ar|they're\} likewise broken away at however the programmers are acting with adroitness to hack information and 
moreover styles new methods to prevent programmer's aims. Any methods that tries to boost the implanting payload or vigor ought to shield subtlety. Numerous implanting payload could effectsly have an effect on sound quality. During this venture, LSB strategy used for sound video steganographyas to urge productive outcomes and with less bending.

\section{Background and literature review}

Steganography has been perform in 2 space: Temporal space \&amp; Transform space. The steganography ought to be doable in numerous strategies, let's say, LSB coding, Parity cryptography, Echo concealing, part cryptography, unfold Spectrum, wave space. The planned technique is connected to completely different sound documents, let's say, discourse and music envelope signals. These sound documents were used as spreads and mystery messages and everything giving noteworthy outcomes on steganography plan [1]. A calculation for concealing image in chosen video arrangement could be a image concealing procedure in lightweight of separate wave remodel (DWT) and Singular price Decomposition (SVD) and irregular LSB (Least vital Bit). This strategy is employed that decreases the putting in injury of the host sound record. The strategy centers the chance of computer legal sciences technique which is use as associate equipment for confirmation and knowledge security reason and its utilization in video steganography in security approach [2]. The Genetic formula directors ar used to urge the leading edge chromosomes. Next choose the simplest body as indicated by the simplest eudaemonia esteem. eudaemonia esteem is associate estimation of LSB position that we tend to get a body with the bottom deviation contrastive with the primary host sound example. Here higher LSB layer is given higher inclination if there ought to arise an incident of layer determination. the primary sound example and embeddings message bit in numerous LSB layer positions we tend to get some new examples. In some cases it will happen that for in way over one LSB layer and obtain an identical distinction between distinctive sound example and new sound examples. For this case, we'll choose the upper LSB layer .The cryptography half gets befuddled as thelong instant message cannot be shrouded utilizing these strategy [6]. This strategy approach confront acknowledgment system utilizing PCA calculation. In PCA based mostly face acknowledgment the calculation for current external body part following is patterned it out. The calculation takes the well-liked posture not simply of geometric relations between an individual's face, however additionally of a good part extraction. during this framework PCA is employed for highlight extraction and Genetic formula is employed for acknowledgment [9].

\section{Proposed system}

\section{Block diagram}

\section{Encryption}

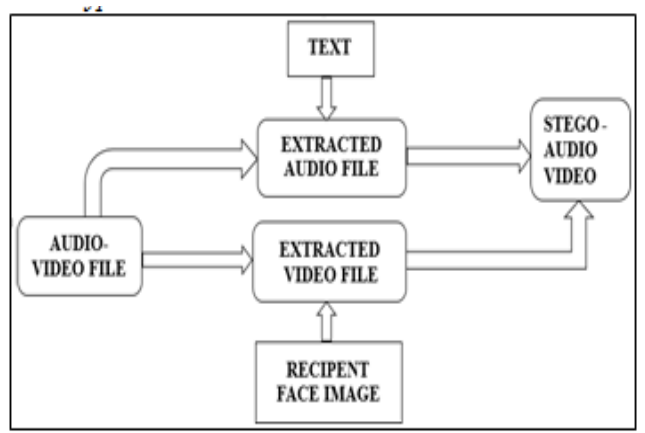

Fig. 1: Encryption process of proposed system

In Fig.1, the square graph of concealing content substance behind sound is appeared. Any open .mp4 sound video document is chosen. Following stage is to extricate sound from chose .mp4 record, and separate the sound and video part. Behind extricated sound conceal the mystery content and behind separated video shroud the beneficiary face picture. At long last the stego sound video record is produced at the sender side.

\section{Decryption}

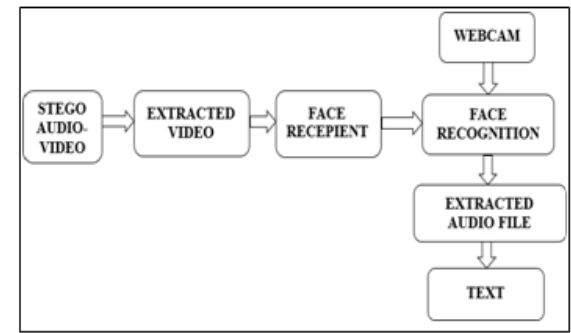

Fig. 2: Decryption process of proposed system

In Fig.2, at collector side the stego sound video record is showed up, at that point select the extricated video part and recuperate the approved beneficiary's face picture from the chose outline. Contrast recouped approved face picture and the information picture from webcam. On the off chance that both the pictures are verified, at that point no one but client can recoup the content behind sound else process will hold up until the point that approved beneficiary shows up before webcam. At the point when verification system is done it will have the capacity to remove mystery content from stego-sound document.

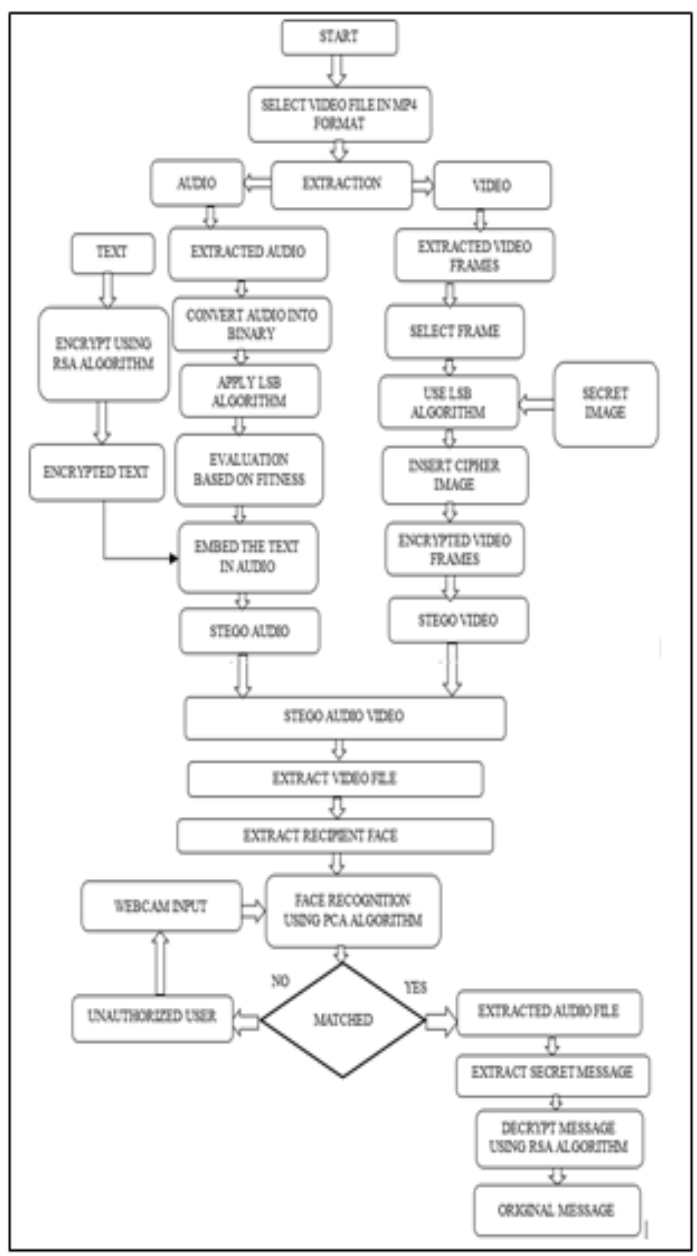

Fig. 3: Flowchart of framework stream

In Fig.3, the message is ingrained in sound by following approach as projected framework is utilizing the video record (.mp4) for 
doing the complete system, initial the video document is isolated in 2 distinctive areas that's separated sound and video record. each the segments play out a vital half to execute the likelihood of the endeavor, the removed sound record is use for concealing the mystery message before concealing, the content is encoded utilizing RSA calculation this calculation utilizes 2 keys for cryptography and unscrambling here open secret's use for cryptography. These procedure is use to form the knowledge safer, when these concealing half is completed by LSB calculation. The LSB calculation is less complicated and generally utilize calculation because it offers the simplest position in sound to hide the content in order that there's less twisting in stego-sound record, during this manner the distinction between distinctive sound and stego-sound is a smaller amount. Presently the removed video record is use for concealing the face image of approve individual to whom the mystery info is projected to send these strategy prompts the event of stego-video. When this each stego records ar joined to border the stego sound video document. Presently the secret writing is perform to induce the hid mystery message from stego sound video document in secret writing half the video record is faraway from stego sound video document to recuperate the validation image from chosen define, at that time the face input is taken from digital camera for confirmation reason and therefore the data image is coordinated with the shrouded image, the face acknowledgment is finished utilizing PCA calculation, the PCA calculation checks the info|the knowledge|the data\} image on premise of the Manfred Eigen estimations of face image store in video define on the off probability that it gets coordinated the sound half is free to induce the mystery information from it .After separating the shrouded content the content is unscrambled utilizing personal key of RSA calculation for obtaining the primary mystery message.

\section{Experimental results}

\section{Encryption}

\section{Audio extraction}

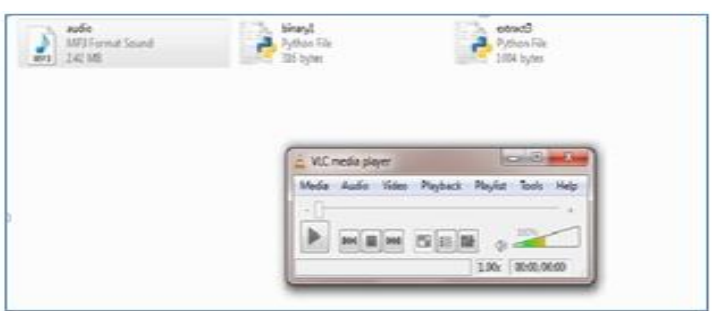

Fig. 4: Audio extraction process

The video document .mp4 organization of size zero.99Mb is chosen. At that time sound and video area unit separated from mp4 video document. The separated sound record estimate is one. $96 \mathrm{Mb}$. This freed sound document is within the mp3 organize. Presently behind this removed sound record the mystery message is inserted by projected calculation.

\section{Audio in binary format}

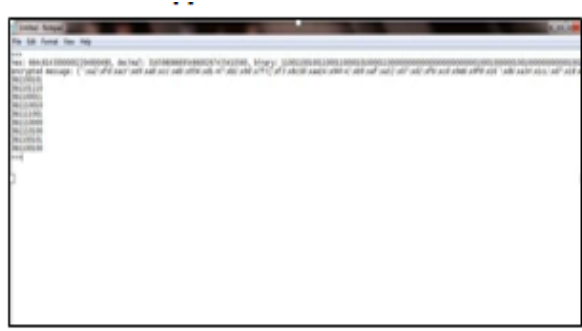

Fig. 5: Audio in binary format
Initially the moment message is disorganized utilizing RSA calculation. At that time that disorganized message is modified over into double organization for these disentangled sound document is utilize and altered over that record into parallel configuration.

\section{Stego-audio is created}

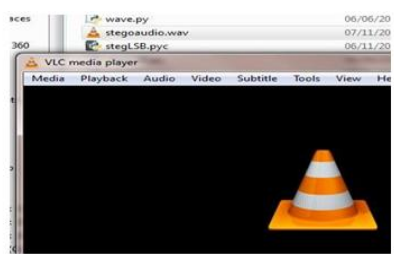

Fig. 6: Stegoaudio

Stego-audio is created by covering up encoded message behind sound utilizing LSB calculation.

\section{Created format}

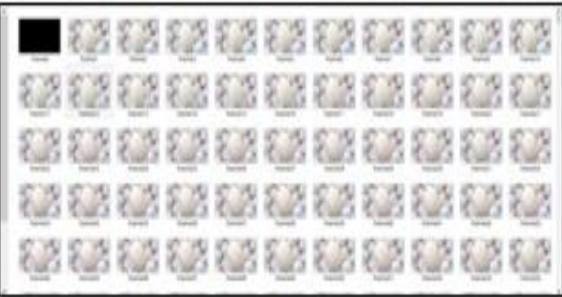

Fig. 7: Created format

For video part, extricated video record in the .avi arrangement and size is $696 \mathrm{~KB}$, at that point video is changed over into outlines. Each casing size is $23 \mathrm{~KB}$. From outlines made a solitary edge is chosen to conceal the beneficiary picture behind the chose outline

\section{Audio response}

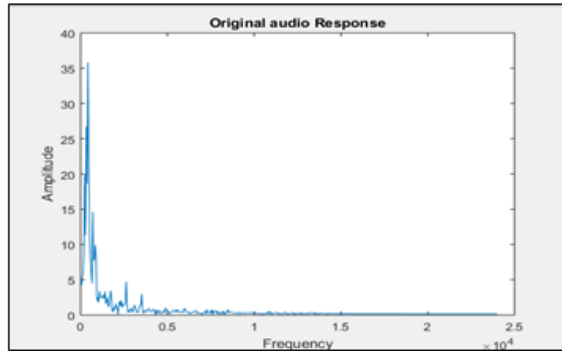

Fig.8(a): Original audio response

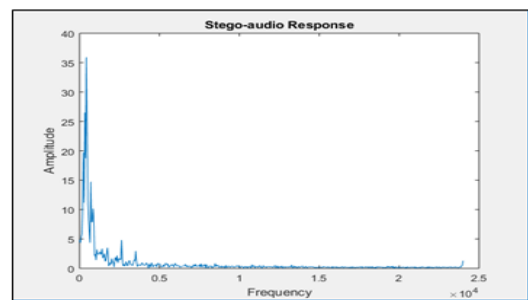

Fig. 8(b): Stego audio response

It is seen from each the Fig. 8(a) and 8(b)that there's no adjustment in waveforms.Each the waveforms ar indistinguishable; it implies there's no adjustment in attributes of sound flag once put in with info.

Stego video 


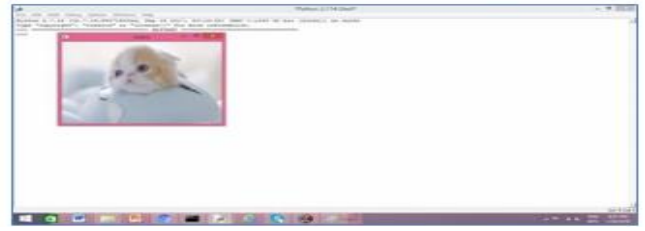

Fig. 9: Stego video

In Fig. 9, the stego video is created by combining the all separated frames with stego frame.

\section{Comparison of various videos}

Table 1: Comparison of Various Frames

\begin{tabular}{|c|r|r|}
\hline VID E O S & FRAMES & SIIE OF FRAMI \\
\hline Video1(0.99MB) & 576 & $16.9 \mathrm{~KB}$ \\
\hline Video 2(8.7MB) & 1410 & $1.1 .8 \mathrm{~KB}$ \\
\hline Video 3(14.1MB) & 326 & $175 \mathrm{~KB}$ \\
\hline
\end{tabular}

\section{Conclusion}

Concealing knowledge could acquaint enough obvious clamor with raise doubt. on these lines the bearer or cowl sound should be fastidiously chosen. This projected framework is to present a good, productive strategy for securing the knowledge from applied scientist and sent to the goal in a very protected means. Implanting image and content behind video and sound document and at the moment consolidate into stego record at sender facet and from that time confront verification procedure is completed at beneficiary facet to cross check the security parameter by approving the beneficiary later ,the information is altogether secured. The mystery content knowledge is chronicle in sound effectively to boot translates the sound document and targeted to separate mystery content.

\section{Future work}

The work exhibited during this task is, ideally enclosed within the characterized scope during this means, future unscrambling analysis is relied upon to analyze past the extent of this project. The viability and proficiency of the projected framework are often upgraded within the methodology for limit, security and strength. In any case, no matter whether or not the projected strategy are often recognized by alternative high-measurements steganalytic calculations have to be compelled to be to boot examined. the longer term work essentially centers around sound video steganography with befuddling calculation and reversible info concealing system. As these task has prevailing in secret writing a \{part of it consequently the cryptography part are often performed through reversible info concealing strategy the right image and knowledge are often recovered aboard the duvet video and sound. The sound and video quality will likewise be protected.

\section{References}

[1] Tayel M, Gamal A \& Shawky H, "A proposed implementation method of an audio steganography technique", 18th International Conference on Advanced Communication Technology (ICACT), (2016), pp.180-184.

[2] Kakde Y, Gonnade P \& Dahiwale P, "Audio-video steganography", International Conference on Innovations in Information, Embedded and Communication Systems (ICIIECS), (2015), pp.1-6.

[3] Blue J, Condell J \& Lunney T, "Identity Document Authentication using Steganographic Techniques", Signal and System Conference (ISSC), (2017).

[4] Gambhir A \& Khara S, "Integrating RSA Cryptography \& Audio Steganography", International Conference on Computing, Communication and Automation (ICCCA), (2016).
[5] Chowdhury R, Bhattacharyya D, Bandyopadhyay SK \& Kim TH, "A view on LSB based audio steganography", International Journal of Security and Its Applications, Vol.10, No.2 (2016), pp.51-62.

[6] Santhi V \& Govindaraju L, "Stego-audio Using Genetic Algorithm Approach", Research Journal of Applied Sciences, Engineering and Technology, (2014).

[7] Johri P \& Kumar A, "Review paper on text and audio steganography using GA", International Conference on Computing, Communication \& Automation, (2015), pp. 190-192.

[8] Bhowal K, "Audio Steganography using GA", International Conference on Computational Intelligence and Communication Networks, (2010).

[9] Mahmud F, Haque ME, Zuhori ST\& Pal B, "Human face recognition using PCA based Genetic Algorithm", International Conference on Electrical Engineering and Information \& Communication Technology (ICEEICT), (2014), pp.1-5. 